\title{
Biocatalytic Reductive Amination by Native Amine Dehydrogenases to Access Short Chiral Alkyl Amines and Amino Alcohols
}

Laurine Ducrot ${ }^{1}$, Megan Bennett ${ }^{2}$, Adam A. Caparco ${ }^{3}$, Julie A. Champion ${ }^{3}$, Andreas S. Bommarius ${ }^{3}$, Anne Zaparucha ${ }^{1}$, Gideon Grogan ${ }^{2}$ and Carine Vergne-Vaxelaire ${ }^{1 *}$

${ }^{1}$ Génomique Métabolique, Genoscope, Institut François Jacob, CEA, CNRS, Univ Evry, Université Paris-Saclay, Evry, France, ${ }^{2}$ York Structural Biology Laboratory, Department of Chemistry, University of York, York, United Kingdom, ${ }^{3}$ School of Chemical and Biomolecular Engineering, Georgia Institute of Technology, Atlanta, GA, United States

\section{OPEN ACCESS}

Edited by:

Francesca Paradisi,

University of Bern, Switzerland

Reviewed by:

Elaine O'Reilly,

University College Dublin, Ireland

Jan von Langermann,

University of Rostock, Germany

*Correspondence:

Carine Vergne-Vaxelaire carine.vergne@genoscope.cns.fr

Specialty section: This article was submitted to Biocatalysis,

a section of the journal

Frontiers in Catalysis

Received: 22 September 2021

Accepted: 29 October 2021

Published: 26 November 2021

Citation:

Ducrot L, Bennett M, Caparco AA,

Champion JA, Bommarius AS,

Zaparucha A, Grogan $G$ and Vergne-Vaxelaire $C$ (2021) Biocatalytic Reductive Amination by Native Amine

Dehydrogenases to Access Short

Chiral Alkyl Amines and

Amino Alcohols.

Front. Catal. 1:781284.

doi: 10.3389/fctls.2021.781284
Small optically active molecules, and more particularly short-chain chiral amines, are key compounds in the chemical industry and precursors of various pharmaceuticals. Their chemo-biocatalytic production on a commercial scale is already established, mainly through lipase-catalyzed resolutions leading to ChiPros ${ }^{\mathrm{TM}}$ products among others. Nevertheless, their biocatalytic synthesis remains challenging for very short-chain $\mathrm{C} 4$ to C5 amines due to low enantiomeric excess. To complement the possibilities recently offered by transaminases, this work describes alternative biocatalytic access using amine dehydrogenases (AmDHs). Without any protein engineering, some of the already described wild-type AmDHs (CfusAmDH, MsmeAmDH, MicroAmDH, and MATOUAmDH2) were shown to be efficient for the synthesis of hydroxylated or unfunctionalized small 2-aminoalkanes. Conversions up to $97.1 \%$ were reached at $50 \mathrm{mM}$, and moderate to high enantioselectivities were obtained, especially for (S)-1methoxypropan-2-amine (98.1\%), (S)-3-aminobutan-1-ol (99.5\%), (3S)-3-aminobutan-2ol (99.4\%), and the small (S)-butan-2-amine (93.6\%) with MsmeAmDH. Semi-preparative scale-up experiments were successfully performed at $150 \mathrm{mM}$ substrate concentrations for the synthesis of (S)-butan-2-amine and (S)-1-methoxypropan-2-amine, the latter known as "(S)-MOIPA". Modeling studies provided some preliminary results explaining the basis for the challenging discrimination between similarly sized substituents in the active sites of these enzymes.

Keywords: native amine dehydrogenases, reductive amination, short chiral amines, amino alcohols, (S)-MOIPA, (S)butan-2-amine

\section{INTRODUCTION}

Short-chain chiral amines with carbon chain lengths ranging from $\mathrm{C} 1$ to $\mathrm{C} 5$ have a wide range of applications in the chemical industry as precursors of pharmaceuticals and agrochemicals (Wu et al., 2021). For example, the butan-2-amine substructure is present in the herbicide Bromacil commercialized as the racemate and in the drug candidate XL888. When substituted with a hydroxyl group, the resulting highly functionalized chiral amino alcohols serve as chiral auxiliaries or ligands in various asymmetric syntheses (Ager et al., 1996). Key examples of these 
<smiles>CC[C@H](C)Nc1cc(C(=O)NC2CC3CCC(C2)N3c2ccc(C(=O)C3CC3)cn2)c(C)cc1C(N)=O</smiles>

XL888<smiles>COc1cc2c(cc1Cc1cccc(Cl)c1F)c(=O)c(C(=O)O)cn2[C@H](CO)C(C)C</smiles>

Elvitegravir (one of Stribild ${ }^{\circledR}$ )<smiles>CCC(C)n1c(=O)[nH]c(C)c(Br)c1=O</smiles>

Bromacil<smiles>COC[C@H](C)N(C(=O)CCl)c1c(C)csc1C</smiles>

Outlook $^{\circledast}$<smiles>C[C@@H]1CCO[C@@H]2Cn3cc(C(=O)NCc4ccc(F)cc4F)c(=O)c(O)c3C(=O)N12</smiles>

Dolutegravir (Tivicay $\left.{ }^{\circledR}\right)$

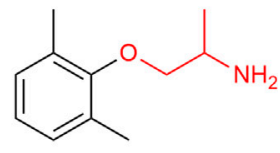

Mexiletine

FIGURE 1 | Structures of some active components of pharmaceuticals and agrochemicals containing short chiral amines. The chiral amino moieties are highlighted in red.

important structural moieties are L-valinol and (R)-3aminobutan-1-ol $((R)$-ABOL), intermediates in the synthesis of HIV integrase inhibitors Elvitegravir (Japan Tobacco, Gilead Sciences) and Dolutegravir (GSK, Pfizer, Shionogi Limited) respectively, (S)-MOIPA, a key chiral element within the herbicide Outlook ${ }^{\circledast}$ (BASF), or 2-aminopropan-1-ol, the main building block of the antiarrhythmic agent Mexiletine (Figure 1).

All of these key small chemical entities are industrially produced by well-established traditional synthetic routes, but green alternatives such as biocatalytic access are topics of great interest in the current context of waste reduction and sustainable chemistry. The ChiPros ${ }^{\mathrm{TM}}$ process of BASF based on lipasecatalyzed acetylation is highly efficient for the kinetic resolution of many alkyl amines, such as (S)-1phenylbutylamine or (S)-2-aminononane, with $E$ values of $>1,000$. Nevertheless, in the case of small alkyl amines, $E$ values are much lower $\left(E_{\text {butan-2-amine }}=8, E_{(R)-\mathrm{ABOL}}<10, E_{2-}\right.$ aminopentane $=50$, and $E_{3 \text {-methylbutan-2-amine }}=80$ ) due to the similar size of the R-groups, and their resolution requires more expensive acyl donors or solvents. Therefore, biocatalyzed enantioselective syntheses of these molecules are particularly challenging. Some success has already been reported with transaminases (TAs). BASF has completed the process development of $(R)-\mathrm{ABOL}$ 2.0 with ee values of $>99.9 \%$ (Ditrich, 2020). Kroutil and colleagues have produced both enantiomers of Mexiletine in up to $>99 \%$ ee by deracemization using $\omega$-TA transaminase chemistry (Koszelewski et al., 2009), and (R)- or (S)-butan-2amine has been efficiently synthesized by continuous-flow chemistry using covalently immobilized transaminases * RTA43 and HEwT_F84W, respectively (Heckmann et al., 2021).
$\omega$-Transaminases have also been proved to be useful tools for the asymmetric amination of $a$-hydroxy ketones, either alone or in cascade reactions for the synthesis of chiral vicinal amino alcohols (Gomm and O'Reilly, 2017; Slabu et al., 2017; Patil et al., 2018a). The requirement of transaminases for the addition of an excess of the amino donor that is sacrificed during the process alongside in situ by-product removal or in situ product removal for example using supported liquid membrane (Rehn et al., 2016) pushed the search for alternative enzymes. Enzymes performing proper reductive amination have emerged as promising biocatalysts for the synthesis of optically active amines. Thanks to the recent discovery of native Amine Dehydrogenases (AmDHs) and Reductive Aminases (RedAms), such enzymes are no longer restricted to engineered Amino Acid Dehydrogenases (engAADHs) (Ye et al., 2015; Patil et al., 2018b; Cheng et al., 2020; Ducrot et al., 2020; Cosgrove et al., 2021; Mutti and Knaus, 2021). Although they are described to be active toward a wide range of carbonyl-containing compounds, only a few examples are reported for the synthesis of small chiral alkyl amines and small amino alcohols. These include the engineered L-AmDHTV (mutant D32A/F101S/C290V of L-AmDH) (Franklin et al., 2020) and the mutant AmDH-M (mutant K68T/N261L of LfLeuAADH) (Chen et al., 2019). We recently described native AmDHs from biodiversity and provided a picture of their substrate scope (Mayol et al., 2019; Caparco et al., 2020). Their top tested substrates were mainly cyclohexanone and isobutyraldehyde, but some of them displayed activity toward alkyl linear ketones such as pentan-2-one enabling the biocatalytic synthesis of the corresponding $(S)$-amines on a 


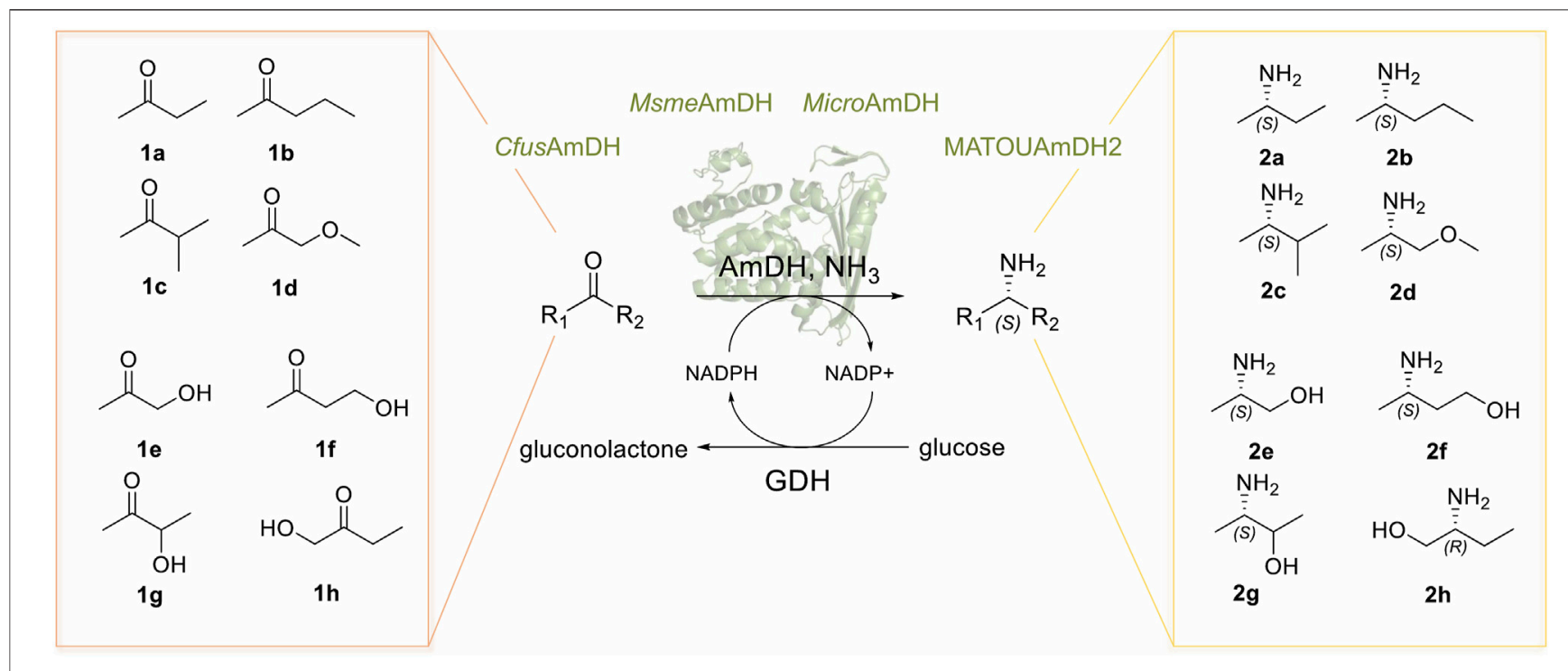

FIGURE 2 | Reductive amination reactions catalyzed by native AmDHs detailed in this study. GDH = glucose dehydrogenase.

millimolar scale (Mayol et al., 2019). The high enantiomeric excess $(e e>97 \%)$ in favor of the $(S)$-amines obtained in these cases prompted us to consider that high enantioselectivity could be achieved for other small chiral amines. In the present work, we sought to study in more detail the biocatalytic potential of some of these native AmDHs (CfusAmDH, MsmeAmDH, MicroAmDH, and MATOUAmDH2) for the synthesis of small chiral alkyl amines and small amino alcohols 2a-h (Figure 2).

\section{MATERIALS AND METHODS}

\section{Chemicals and Materials}

All reagents were purchased from commercial sources and used without additional purification, except in-house (S)-pentan-2amine (S)-2b (Mayol et al., 2019). Butan-2-one (1a), pentan-2one (1b), 1-methoxypropan-2-one (1d), 4-hydroxybutan-2-one (1f), 1-hydroxypropan-2-one (1e), 3-hydroxybutan-2-one (acetoin; 1g), 2-aminopropan-1-ol (alaninol; 2e), butan-2amine (2a), pentan-2-amine (2b), 3-methylbutan-2-amine (2c), 1-methoxypropan-2-amine (2d), 2-aminobutan-1-ol (2h), (S)butan-2-amine ((S)-2a), (R)-3-methylbutan-2-amine $((R)$-2c), (S)-1-methoxypropan-2-amine $((S)$-2d), (S)-2-aminopropan-1ol (S-alaninol; (S)-2e), (S)-2-aminobutan-1-ol ((S)-2h), $\beta$-nicotinamide adenine dinucleotide phosphate disodium salt $\left(\mathrm{NADP}^{+}\right)$, glucose dehydrogenase (GDH105), (S)-2-(5-fluoro2,4-dinitrophenylamino)propanamide (FDAA), and benzoyl chloride $(\mathrm{BzCl})$ were purchased from Merck/Sigma-Aldrich (St. Louis, MO, United States). 3-Methylbutan-2-one (1c), 1hydroxybutan-2-one (1h), 3-aminobutan-1-ol (2f), 3aminobutan-2-ol (2g), (R)-3-aminobutan-1-ol ((R)-2f), and $(2 R, 3 S)$-3-aminobutan-2-ol $((2 R, 3 S)$-2g) were purchased from Enamine Ltd. (Kiev, Ukraine). Buffers were produced from substances purchased from Sigma-Aldrich and adjusted to the desired $\mathrm{pH}$ value with ammonium hydroxide $30 \%$. UHPLC-UV analysis were performed on a UHPLC U3000 RS 1034 bar system (Thermo Fisher Scientific, Waltham, MA, United States) equipped with a UV detector, using a Kinetex F5 column $(100 \mathrm{~mm} \times 2.1 \mathrm{~mm} ; 1.7 \mu \mathrm{m}) \quad$ (Phenomenex, California, United States). NMR spectra were recorded on a Bruker (Bruker, Billerica, MA, United States) $600-\mathrm{MHz}$ spectrometer (Evry University, France) for ${ }^{1} \mathrm{H}$ and ${ }^{13} \mathrm{C}$ experiments. Chemical shifts (expressed in ppm) of ${ }^{1} \mathrm{H}$ and ${ }^{13} \mathrm{C}$ spectra were referenced to the solvent peak $\delta(\mathrm{H})=4.79$ for $\mathrm{D}_{2} \mathrm{O}$.

\section{Large-Scale Purification of Amine Dehydrogenases}

Large-scale purification of MsmeAmDH, CfusAmDH, MicroAmDH, and MATOUAmDH2 was conducted using $2 \times$ $500 \mathrm{ml}$ culture by nickel affinity chromatography (His Trap FF $5 \mathrm{ml}$ ) in tandem with gel filtration (Hi Load 16/60 Superdex 200pg) as described elsewhere (Mayol et al., 2019). The storage buffer was $50 \mathrm{mM} \mathrm{NaCl}, 50 \mathrm{mM}$ sodium phosphate $\mathrm{pH}$ 7.5-8.0, glycerol $10 \%-15 \%$, and $1 \mathrm{mM}$ DTT. Protein concentrations were determined by the Bradford method with bovine serum albumin as the standard (Bradford, 1976). The samples were analyzed by SDS-PAGE using the Invitrogen NuPAGE system. The purified proteins were stored at $-80^{\circ} \mathrm{C}$.

\section{Screening of MsmeAmDH, CfusAmDH, MicroAmDH and MATOUAmDH2 for Conversion of Short Alkyl (Hydroxyl) Ketones}

The selected AmDHs (CfusAmDH, MsmeAmDH, MicroAmDH, and MATOUAmDH2), were tested toward ketones $\mathbf{1 a - 1 h}$ in a 96-well plate with a cofactor regeneration system using UHPLCUV monitoring. To a reaction mixture (total volume $=100 \mu \mathrm{l}$ ) containing $0.2 \mathrm{mM} \mathrm{NADP}{ }^{+}, 11 \mathrm{mM}$ or $55 \mathrm{mM}$ glucose (1.1 eq.), 
and $3 \mathrm{U} \mathrm{ml}^{-1} \mathrm{GDH} 105$ in $2 \mathrm{M} \mathrm{NH}_{4} \mathrm{HCO}_{2}$ buffer, $\mathrm{pH}$ 9.0, was added $10 \mathrm{mM}$ or $50 \mathrm{mM}$ (final concentration) of substrate followed by $0.5 \mathrm{mg} \mathrm{ml}^{-1}$ of purified AmDH. The 96-well plate was covered with an aluminum thermowell sealer and a lid and left for $24 \mathrm{~h}$ at $30^{\circ} \mathrm{C}$ in a thermocontrolled oven. The 96well plate contained wells with background reactions performed in the same manner but lacking the substrate or the purified $\mathrm{AmDH}$, together with wells with calibration mixtures containing $2 \mathrm{M} \mathrm{NH} \mathrm{NH}_{4} \mathrm{HCO}_{2}$ buffer $\mathrm{pH} 9.0$ and various concentrations of amines $(2,4,6$, and $8 \mathrm{mM}$ for $10 \mathrm{mM}$ reactions and $10,20,30$, and $40 \mathrm{mM}$ for $50 \mathrm{mM}$ reactions). All the wells were analyzed by UHPLC-UV after derivatization with $\mathrm{BzCl}$ in 96-well plates. The amounts of amines in reaction mixtures were deduced from calibration curves obtained from the UV-response of the calibration mixtures of racemic $\mathbf{2 a - 2 h}$ (Supplementary Figures S1, S2). Enantiomeric excess of products $\mathbf{2 a}-\mathbf{2 h}$ and diastereoisomeric excess for $\mathbf{2 g}$ were determined after derivatization with FDAA in 96-well plates for UHPLC-UV detection (Supplementary Figure S3). The reactions were performed in duplicate or triplicate at different days to ensure reliable reproducibility.

\section{Derivatization Procedures and UHPLC-UV Conditions}

$\mathrm{BzCl}$ derivatization: $20 \mu \mathrm{l}$ of each reaction mixture was mixed with $50 \mu \mathrm{l}$ of a $200 \mathrm{mM} \mathrm{Na} \mathrm{CO}_{3} / \mathrm{NaHCO}_{3}$ aqueous solution, $\mathrm{pH}$ 9.5, and then mixed with $30 \mu \mathrm{l}$ of a $50 \mathrm{mM} \mathrm{BzCl}$ solution in acetonitrile $(\mathrm{MeCN})$. The derivatization reaction was left for $40 \mathrm{~min}$ at room temperature for reactions in a 96-well plate (or vortexed for $30 \mathrm{~s}$ in case of reactions in microtubes) and then quenched by the addition of $20 \mu \mathrm{l}$ of a $1 \mathrm{M} \mathrm{HCl}$ aqueous solution and $30 \mu \mathrm{l}$ of a $1 / 1$ solution of $\mathrm{H}_{2} \mathrm{O} / \mathrm{ACN}$. After centrifugation $\left(1,008 \mathrm{~g}, 5 \mathrm{~min}, 4^{\circ} \mathrm{C}\right)$ on a $0.22-\mu \mathrm{m}$ filtration $96-$ well plate (or with $0.22-\mu \mathrm{m}$ syringe filters in case of derivatization in microtubes), the filtrates were analyzed by UHPLC-UV (eluent $\mathrm{MeCN} / \mathrm{H}_{2} \mathrm{O}+0.1 \%$ formic acid with a linear gradient $20 / 80$ during $1 \mathrm{~min}$, then $20 / 80$ to $70 / 30$ in $3 \mathrm{~min}$, then $70 / 30$ during

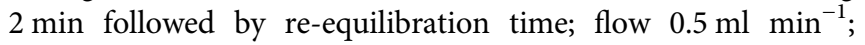
temperature $25^{\circ} \mathrm{C}$; injection volume $3 \mu \mathrm{l} ; \lambda=250 \mathrm{~nm}$ ).

FDAA derivatization: $20 \mu \mathrm{l}$ of each reaction mixture was mixed with $8 \mu \mathrm{l}$ of a $1 \mathrm{M} \mathrm{NaHCO}$ aqueous solution, $\mathrm{pH} 8.0$, and then mixed with $20 \mu \mathrm{l}$ of a $15 \mathrm{mM}$ FDAA solution in $1 / 1$ acetone/EtOH. The derivatization reactions were left $2 \mathrm{~h}$ at $55^{\circ} \mathrm{C}$ for reactions in a 96-well plate (or stirred at $600 \mathrm{rpm}$ for $2 \mathrm{~h}$ at $65^{\circ} \mathrm{C}$ in case of reactions in microtubes), and then quenched by the addition of $4 \mu \mathrm{l}$ of a $2 \mathrm{M} \mathrm{HCl}$ aqueous solution and $80 \mu \mathrm{l}$ of a $1 / 1$ solution of $\mathrm{H}_{2} \mathrm{O} / \mathrm{MeOH}$. After centrifugation $(1,008 \mathrm{~g}, 5 \mathrm{~min}$, $5^{\circ} \mathrm{C}$ ) on a $0.22-\mu \mathrm{m}$ filtration 96 -well plate (or with $0.22 \mu \mathrm{m}$ syringe filters in case of derivatization in microtubes), the filtrate was analyzed by UHPLC-UV (eluent $\mathrm{MeOH} / \mathrm{H}_{2} \mathrm{O}+0.1 \%$ formic acid with a linear gradient $40 / 60$ to $80 / 20$ in $5 \mathrm{~min}$, then $80 / 20$ during

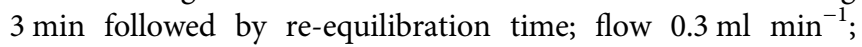
temperature $25^{\circ} \mathrm{C}$; injection volume $3 \mu \mathrm{l} ; \lambda=340 \mathrm{~nm}$ ). In the case of $2 \mathbf{a}$, the eluent was as follows: a linear gradient $30 / 70$ to $80 /$ 20 in $10 \mathrm{~min}$, then $80 / 20$ during $3 \mathrm{~min}$ followed by reequilibration time.

\section{Effect of Substrate Loadings on Conversion of 1-Methoxypropan-2-one and Butan-2-one}

The tolerance of MsmeAmDH to higher substrate concentrations was studied by monitoring the conversion of 1-methoxypropan2-one (1d) into (S)-1-methoxypropan-2-amine (2d) and butan2-one (1a) to (S)-butan-2-amine (2a) for 24-48 h. Reaction mixtures $(100 \mu \mathrm{l})$, containing $0.2 \mathrm{mM} \mathrm{NADP}{ }^{+}, 1.1$ eq. of glucose, $3 \mathrm{U} \mathrm{ml}^{-1} \mathrm{GDH} 105$ in $2 \mathrm{M} \mathrm{NH}_{4} \mathrm{HCO}_{2}$ buffer, $\mathrm{pH}$ 9.0, $0.5 \mathrm{mg} \mathrm{ml}^{-1}$ or $1 \mathrm{mg} \mathrm{ml}^{-1}$ of purified $\mathrm{MsmeAmDH}$, and substrate at a concentration range of 50 to $200-300 \mathrm{mM}$, were incubated in microtubes at $30^{\circ} \mathrm{C}$ at $400 \mathrm{rpm}$. Aliquots were taken at 24 and $48 \mathrm{~h}$ and diluted in $2 \mathrm{M} \mathrm{NH} \mathrm{NHCO}_{2}$ buffer, $\mathrm{pH}$ 9.0, to reach theoretically $50 \mathrm{mM}$ (or $10 \mathrm{mM}$ for ee value determination) product concentration. Conversion to $(S)$-amines and ee values was determined in 96-well plates by UHPLC-UV after derivatization with $\mathrm{BzCl}$ and FDAA, respectively.

\section{Semi-Preparative Scale Reactions}

1d to 2d: In a 50-ml Greiner tube equipped with a screw cap was poured 1-methoxypropan-2-one (1d) $(7.50 \mathrm{ml}$ of a $1 \mathrm{M}$ stock solution in water, 1 eq., $7.5 \mathrm{mmol})$, distilled water $(14.90 \mathrm{ml})$, $\mathrm{NH}_{4} \mathrm{HCO}_{2}$ buffer, $\mathrm{pH} 9.0$ (10.00 ml of a $10 \mathrm{M}$ stock solution), $\mathrm{NADP}^{+}(2.00 \mathrm{ml}$ of a $5 \mathrm{mM}$ stock solution, 0.001 eq., $0.01 \mathrm{mmol})$, glucose $(9.27 \mathrm{ml}$ of a $0.89 \mathrm{M}$ stock solution, 1.1 eq., $8.25 \mathrm{mmol})$, GDH105 (1.5 ml of a $100 \mathrm{U} \mathrm{ml}^{-1}$ stock solution), and MsmeAmDH purified by gel filtration $(4.83 \mathrm{ml}$ of a $5.2 \mathrm{mg} \mathrm{ml}^{-1}$ stock solution). The reaction was shaken at $30^{\circ} \mathrm{C}$, $300 \mathrm{rpm}$ with UHPLC-UV monitoring after $\mathrm{BzCl}$ derivatization in microtubes (Supplementary Figures S4, S5). Isolation of the product 2d was not performed.

1a to 2a: In a 50-ml Greiner tube equipped with a screw cap was poured butan-2-one $(7.50 \mathrm{ml}$ of a $1 \mathrm{M}$ stock solution in water, 1 eq., $7.5 \mathrm{mmol})$, distilled water $(15.92 \mathrm{ml}), \mathrm{NH}_{4} \mathrm{HCO}_{2}$ buffer, $\mathrm{pH}$ $9.0(10.00 \mathrm{ml}$ of a $10 \mathrm{M}$ stock solution $), \mathrm{NADP}^{+}(2.00 \mathrm{ml}$ of a $5 \mathrm{mM}$ stock solution, 0,001 eq., $0.01 \mathrm{mmol})$, glucose $(8.25 \mathrm{ml}$ of a $1 \mathrm{M}$ stock solution, 1.1 eq., $8.25 \mathrm{mmol}), \mathrm{GDH} 105$ ( $1.5 \mathrm{ml}$ of a 100 $\mathrm{U} \mathrm{ml}^{-1}$ stock solution), and $M$ smeAmDH purified by gel filtration ( $4.83 \mathrm{ml}$ of a $5.2 \mathrm{mg} \mathrm{ml}^{-1}$ stock solution). The reaction was shaken at $30^{\circ} \mathrm{C}, 300 \mathrm{rpm}$ with UHPLC-UV monitoring after $\mathrm{BzCl}$ derivatization in microtubes. After $24 \mathrm{~h}$, the reaction was acidified to $\mathrm{pH}$ 1-2 with concentrated $\mathrm{HCl}$ and concentrated in vacuo to remove unreacted ketone (water bath $45^{\circ} \mathrm{C}, p=$ 35 mbar). After addition of $10 \mathrm{ml}$ of water, the mixture was basified with $\mathrm{KOH} 10 \mathrm{M}$ under cooling by ice bath and distilled under atmospheric pressure. Three fractions were collected [fraction 1: boiling point $(\mathrm{bp}) 65-70^{\circ} \mathrm{C}$, fraction 2 : bp $70-80^{\circ} \mathrm{C}$, fraction 3 : bp $80-85^{\circ} \mathrm{C}$ ]. The three fractions were analyzed by UHPLC-UV and NMR demonstrating the presence of the desired product with more or less water and ammonia salt. The three fractions were combined, acidified with concentrated $\mathrm{HCl}$ (approximatively 2 eq.), and lyophilized. The (2S)-butan-2-amine (2a) was obtained as monohydrochloride salt ( $421 \mathrm{mg}, 51 \%$ yield, white solids) with $92.6 \%$ ee as determined by UHPLC-UV after FDAA derivatization (Supplementary Figures S6-S8). NMR 
(S)-butan-2-amine ((S)-2a)

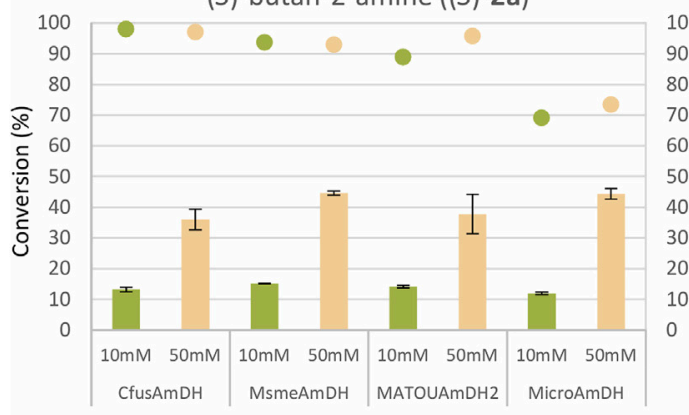

(S)-3-methylbutan-2-amine ((S)-2c)

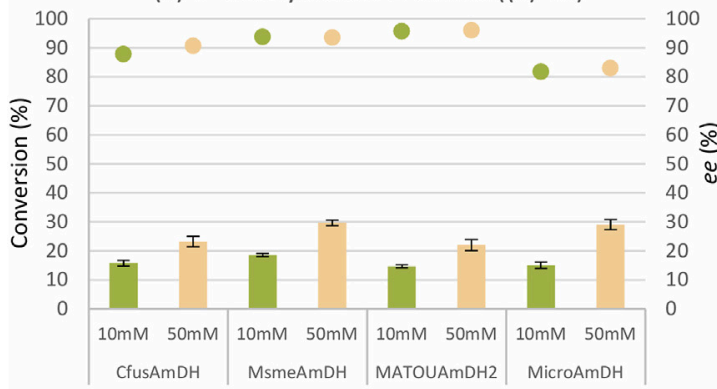

(S)-2-aminopropan-1-ol ((S)-2e)

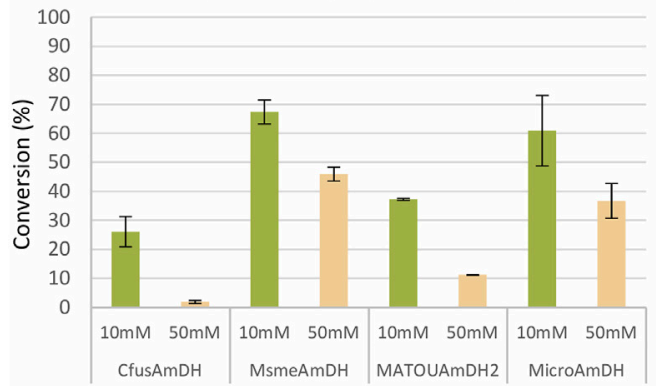

(3S)-3-aminobutan-2-ol ((S)-2g)

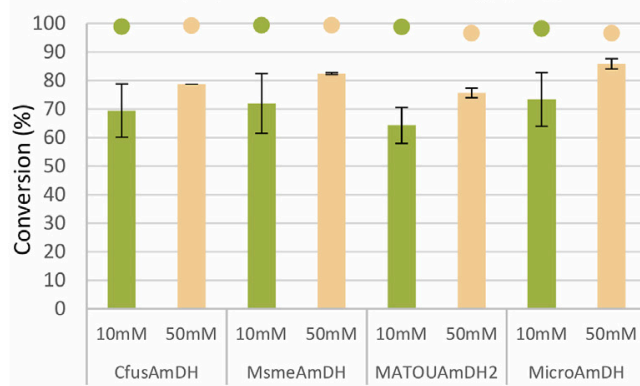

(S)-pentan-2-amine ((S)-2b)

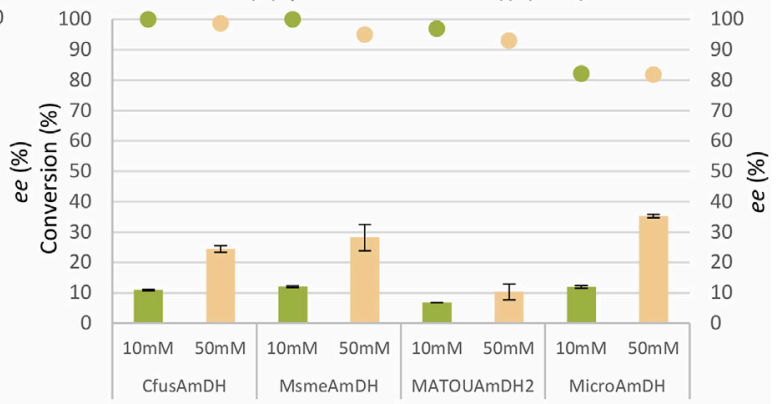

(S)-1-methoxypropan-2-amine ((S)-2d)

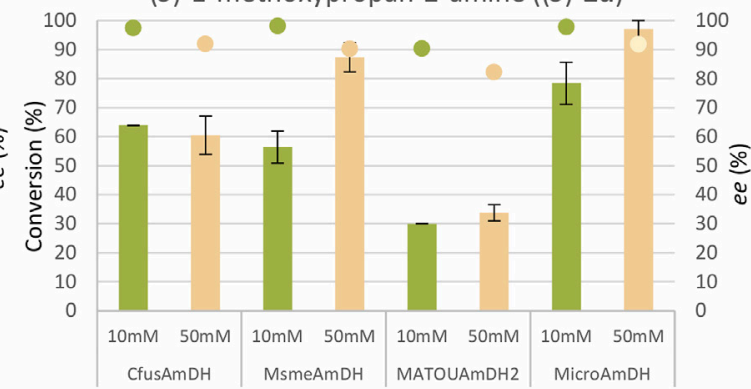

(S)-3-aminobutan-1-ol ((S)-2f)

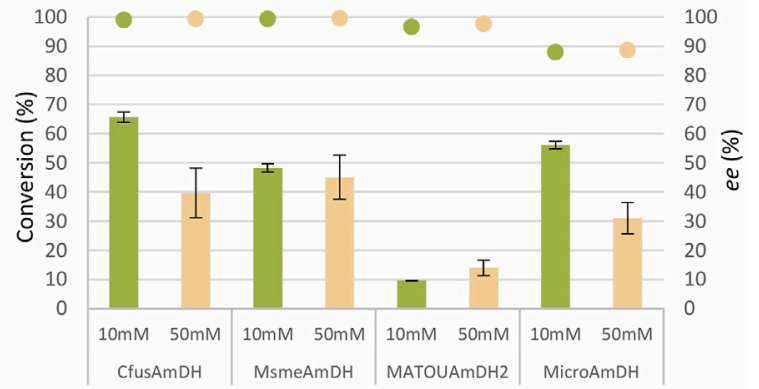

(S)-2-aminobutan-1-ol ((S)-2h)

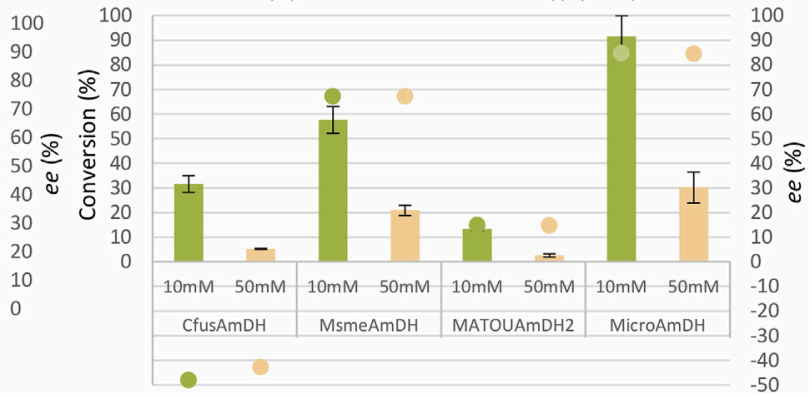

FIGURE 3 | Conversions and enantiomeric excess results with CfusAmDH, MsmeAmDH, MATOUAmDH2, and MicroAmDH. Reactions conditions: $10 \mathrm{mM}$ or $50 \mathrm{mM}$ substrate, $2 \mathrm{M} \mathrm{NH}_{4} \mathrm{HCO}_{2}$ buffer, pH 9.0, $0.2 \mathrm{mM} \mathrm{NADP}^{+}$, 1.1 eq. glucose, $3 \mathrm{U} \mathrm{ml}^{-1} \mathrm{GDH} 105,0.5 \mathrm{mg} \mathrm{ml}^{-1}$ purified AmDH, $24 \mathrm{~h}, 30^{\circ} \mathrm{C}$. Error bars represent standard deviations of two or three independent experiments. Due to coelution with FDAA-derivatized co-product, the enantiomeric excess of (S)-2-aminopropan-1-ol (2e) could not be calculated, but the (S)-enantiomer was the major peak (Supplementary Figure 3E). The data are given in Supplementary Figure S13.

spectra were identical to standard amine commercially available. ${ }^{1} \mathrm{H} \quad \mathrm{NMR} \quad\left(600 \mathrm{MHz}, \mathrm{D}_{2} \mathrm{O}\right) \quad \delta \quad 3.31 \quad(\mathrm{~m}, 1 \mathrm{H})$, $1.57-1.73(\mathrm{~m}, 2 \mathrm{H}), 1.29(\mathrm{~d}, J=6.74 \mathrm{~Hz}, 3 \mathrm{H}), 0.98(\mathrm{t}, J=$ $7.60 \mathrm{~Hz}, 3 \mathrm{H}) .{ }^{13} \mathrm{C}$ NMR $\left(150 \mathrm{MHz}, \mathrm{D}_{2} \mathrm{O}\right) \delta 49.3,27.2,17.2,9.0$. (Supplementary Figures S9-S12).

\section{Modeling and Docking Experiments}

The products $(R / S)$-butan-2-amine (2a), (2R/S)-2-amino-1propanol (2e), and $(2 R / S)$-2-aminobutanol (2h) were docked into the structures MsmeAmDH and CfusAmDH, and into the models of MicroAmDH and MATOUAmDH2 to analyze the 
observed stereoselectivities. Each amine product was docked as their $(R)$ - and $(S)$-enantiomers separately. The ligand PDB files were generated using the CORINA Molecular Online Tool. The docking was done in the RX structures of CfusAmDH (PDB: 6IAU) and MsmeAmDH (PDB: 6IAQ) and in the homology models generated for MicroAmDH (PDB template used: 6IAQ) and MATOUAmDH2 (PDB template used: 6IAU) using SWISSMODEL. With AutoDockTool (Morris et al., 2009), the docking simulations were performed on rigid structures, with no flexibility given to any catalytic pocket residues. The number of Genetic Algorithm (GA) runs were fixed at 50 using the Lamarckian GA (4.2). The 50 ligand conformations obtained were then analyzed in PyMOL.

\section{RESULTS}

\section{Conversions of Various Small Alkyl and Hydroxylated Ketones}

In the context of biocatalytic applications, we aim to explore the synthetic potential of native AmDHs already described mainly through determination of specific activities and kinetic parameters. The AmDHs MsmeAmDH, CfusAmDH, MicroAmDH, and MATOUAmDH2, selected according to their reported substrate profiles, were tested with a cofactor recycling system over $24 \mathrm{~h}$ to provide conversion data with the small alkyl ketones, butan-2-one (1a), pentan-2-one (1b), 3methylbutan-2-one (1c), 1-methoxypropan-2-one (1d), 1hydoxypropan-2-one (1e), 4-hydroxybutan-2-one (1f), 3hydroxybutan-2-one (1g), and 1-hydroxybutan-2-one (1h). Each substrate was tested at 10 and $50 \mathrm{mM}$ to provide preliminary data for biocatalytic syntheses at a more substantial substrate concentration, while using a reasonable amount of purified enzyme $\left(0.5 \mathrm{mg} \mathrm{ml}^{-1}\right)$. All reactions were carried out in 96 -well plates at $30^{\circ} \mathrm{C}$ in ammonium formate buffer, $\mathrm{pH} 9.0$, with a glucose-glucose dehydrogenase $\mathrm{NADP}^{+}$recycling system. The conversions were calculated based on calibration curves obtained with commercialized standards after derivatization of the reaction mixtures with $\mathrm{BzCl}$ and UHPLCUV analysis performed in 96-well plates. The enantiomeric excesses were calculated after UHPLC-UV analysis of the same reactions derivatized with FDAA in a 96-well plate.

The results are shown in Figure $\mathbf{3}$ and detailed in Supplementary Figure S13. At $10 \mathrm{mM}$, low conversions $(6.8 \%-18.5 \%)$ were obtained for small alkyl ketones devoid of any functionality, but interestingly, high ee values (96.0 and 98.1\% respectively) were still recorded in the case of the smallest amine (S)-butan-2-amine (2a) with MsmeAmDH and CfusAmDH, despite the high similarity between the size of each substituent. We note that MATOUAmDH2 and especially MicroAmDH gave lower ee values $(88.9 \%$ and $69.1 \%$, respectively). Conversions and enantioselectivity results for $(S)$ pentan-2-amine (2b) were similar to that previously described for CfusAmDH, despite lower conversions observed experimentally in plates compared to closed microtubes, presumably due to undesired evaporation of the substrate. Very interestingly, good to high conversions of 1-methoxypropan-2-one (1d) to the corresponding amine (S)-MOIPA (2d) were achieved with CfusAmDH (63.9\%), MsmeAmDH (56.5\%), and MicroAmDH (78.4\%). Lower conversions were obtained with MATOUAmDH2 (30.0\%), together with slightly lower ee values (90.4\% against 97.4-98.1) for the three other enzymes. Even more remarkable were the moderate to high conversions obtained with non-protected alcohols. With $10 \mathrm{mM}$ as the starting substrate concentration, the small vicinal amino alcohol (3S)-3-aminobutan2-ol (2g) was obtained with $64.3 \%-73.3 \%$ conversion with the four tested enzymes. For ketones 1e, $1 \mathbf{1 f}$, and $\mathbf{1 h}$ with a terminal alcohol, the conversions were much more dependent on the enzyme. (S)-2aminopropan-1-ol (2e) and (S)-2-aminobutan-1-ol (2h) were formed with low to moderate conversions with $C f u s \mathrm{AmDH}$ and MATOUAmDH2 (26.1\%-31.6\% and $37.2 \%-13.4 \%$, respectively) whereas good conversions were reached with $M s m e A m D H$ and MicroAmDH (67.4\%-57.6\% and 60.9\%-91.5\%, respectively). (S)-3aminobutan-1-ol (2f) was formed with only $9.6 \%$ with MATOUAmDH2, but with $48.2 \%-65.7 \%$ with the other three AmDHs. High stereoselectivity in favor of the $(S)$-enantiomer were confirmed for all these substrates with ee values generally above $96 \%$, except for 2-aminobutan-1-ol (2h) for which an $(R)$ - preference was determined in the case of CfusAmDH, even if the enantiomeric excess was quite low (48.1\%). Taking into account Cahn-Ingold-Prelog rules, this is in accordance with the same positioning of the longest carbon chain of the substrate in the active site. For MsmeAmDH and MicroAmDH, the (S)-amines were formed with $67.0 \%-84.8 \% \mathrm{ee}$, whereas only $14.9 \%$ ee was measured with MATOUAmDH2, in addition to low conversion. Excellent ee values (98.8\%-99.4\%) were particularly obtained for (3S)-3-aminobutan-2-ol (2g) with CfusAmDH, MsmeAmDH and MATOUAmDH2 (98.2\% with MicroAmDH). In case of this chiral substrate, bad diasteroisomeric excess was obtained with the four enzymes (10.4\%-13.0\%, Supplementary Figure S13) showing that they accept both enantiomers at the alcohol position. Overall, MicroAmDH displayed lower enantioselectivities compared to the three other enzymes, particularly for alkylketones $\mathbf{2 a - 2 c}$ and for 2aminopropan-1-ol (2e). For the former, the not quantified $(R)$ enantiomer was present in larger amounts with $\mathrm{MicroAmDH}$ than with other enzymes, for which only traces could be detected. We noted that the four enzymes did not differentiate the stereochemistry at the vicinal $\mathrm{OH}$ position, with the trans/cis ratio ranging from $55.2 \%$ to $56.5 \%$.

At $50 \mathrm{mM}$ substrate, all the conversions were similar or even much higher compared with $10 \mathrm{mM}$ for substrates 1a-1d without any free hydroxyl group, at equivalent concentration of biocatalyst. The conversion of butan-2-one (1a) was 2.7-3.7 times higher at $50 \mathrm{mM}$ than at $10 \mathrm{mM}$. For the one and two more carbon substrates $\mathbf{1 b}$ and $\mathbf{1 c}$, this behavior was also observed but to a lesser extent (1.5-3 times for $\mathbf{1 b}$ and 1.5-1.9 times for $\mathbf{1 c}$ ). With free hydroxylated ketones $\mathbf{1 e}-\mathbf{1 h}$, the increase in substrate concentration was tolerated by the four enzymes for 4-hydroxybutan-2-one (1f) and 3hydroxybutan-2-one (1g) but not for 1-hydoxypropan-2-one (1e) and 1-hydroxybutan-2-one (1h), where significant decreases in conversion were observed. Among the four tested enzymes, CfusAmDH seemed to be the most affected. In terms of enantiomeric excess, overall, the ratio between enzymes for all the tested substrates was approximately conserved. 

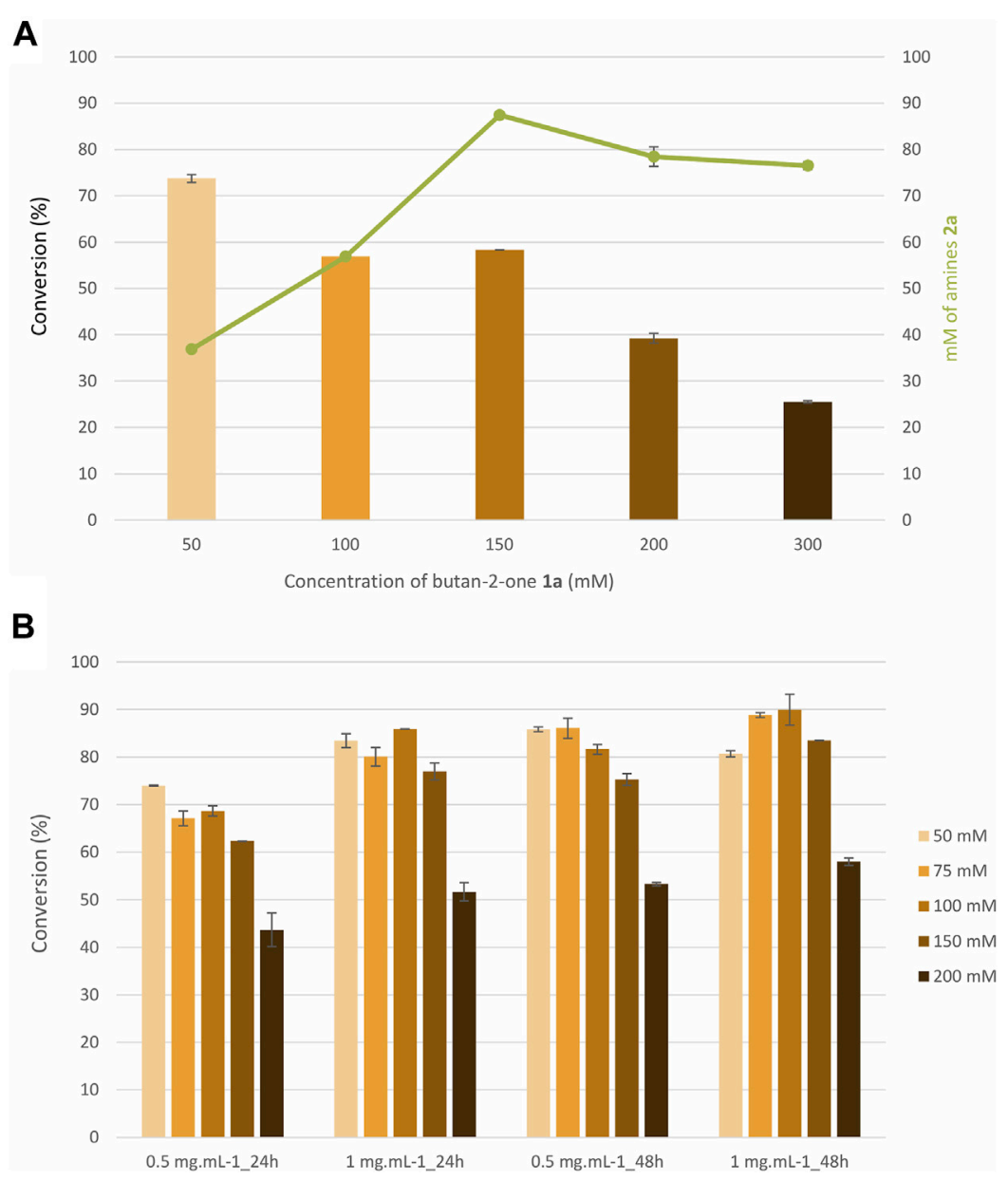

FIGURE 4 | (A) and (B) Effect of concentration in butan-2-one 1a (A) and 1-methoxypropan-2-one 1d (B) on the conversion with MsmeAmDH. Reactions conditions: 10-200 mM substrate, $2 \mathrm{M} \mathrm{NH}_{4} \mathrm{HCO}_{2}$ buffer, pH 9.0, $0.2 \mathrm{mM} \mathrm{NADP}^{+}$, 1.1 eq. glucose, $3 \mathrm{U} \mathrm{ml}^{-1} \mathrm{GDH}_{105}, 0.5 \mathrm{mg} \mathrm{ml}^{-1}$, or $1.0 \mathrm{mg} \mathrm{ml}^{-1}$ purified AmDH, $24 \mathrm{~h}$ or $48 \mathrm{~h}, 30^{\circ} \mathrm{C}$. Error bars represent standard deviations of two independent experiments.

\section{Increase of Butan-2-one and 1-Methoxypropan-2-one Concentration}

Based on the screening results, we were prompted to test an increase in substrate concentration above $50 \mathrm{mM}$ towards the small ketone butan-2-one (1a), which displayed a clear increase in yield between 10 and $50 \mathrm{mM}$. This study was conducted on MsmeAmDH and the reaction was monitored at $24 \mathrm{~h}$ (Figure 4A). The already high ammonia concentration was retained at $2 \mathrm{M}$, the same ratio $\mathrm{NH}_{4}{ }^{+}$/substrate could not be maintained for reasons of solubility and ionic strenghts. The results obtained after UHPLCUV analysis showed that $150 \mathrm{mM}$ of $\mathbf{1 a}$ was still converted in good yield (58.3\%) to the corresponding (S)-amine $2 \mathbf{a}$ with $0.5 \mathrm{mg} \mathrm{ml}^{-1}$ of $M s m e A m D H$ in $24 \mathrm{~h}$. Even if the conversion dropped at $300 \mathrm{mM}$ of substrate, the amount of amine formed was similar to that formed at 150 and $200 \mathrm{mM}$. The calculated ee values were similar for the amine $\mathbf{2 a}$ whatever the initial substrate concentration, i.e., approximately, 91.8\%-92.0\%.

A similar study was performed for 1-methoxypropan-2-one (1d) at two different enzyme loadings (Figure 4B). The conversions were similar at $50-150 \mathrm{mM}$ and decreased
1.4-1.7 times at $200 \mathrm{mM}$ depending on the reaction duration and enzyme concentration. Running the reaction for $48 \mathrm{~h}$ with $0.5 \mathrm{mg} \mathrm{ml}^{-1}$ or $24 \mathrm{~h}$ with twice the amount of enzyme enabled $81.7 \%-85.9 \%$ conversion of $100 \mathrm{mM}$ of ketone, which were roughly the conversions obtained at $50 \mathrm{mM}$ (74.0-85.9\%). At $200 \mathrm{mM}$, the conversions did not exceed 58\% whatever the conditions used, which were still similar to that obtained at $10 \mathrm{mM}$ during the screening in 96-well plates (56.5\%). At $200 \mathrm{mM}$, the space time yields were $5.2-7.9 \mathrm{~g} \mathrm{~L}^{-1}$ day $^{-1}$, depending on the reaction time and enzyme loading.

\section{Semi-preparative Synthesis of (S)-MOIPA ((S)-2d) and (S)-Butan-2-amine ((S)-2a)}

In view of the tolerance to high loadings of 1-methoxypropan-2one 1d and butan-2-one 1a, the semi-preparative syntheses of $(S)$-MOIPA $((S)$-2d) and $(S)$-2a were performed to highlight the potential of these enzymes, and more particularly of wild-type MsmeAmDH. Therefore, the synthesis of $(S)$-MOIPA was carried out at $7.5 \mathrm{mmol}$ scale at $150 \mathrm{mM}$ substrate concentration over $48 \mathrm{~h}$ with $0.5 \mathrm{mg} \mathrm{ml}^{-1}$ of $M s m e A m D H$. Based on calibration 


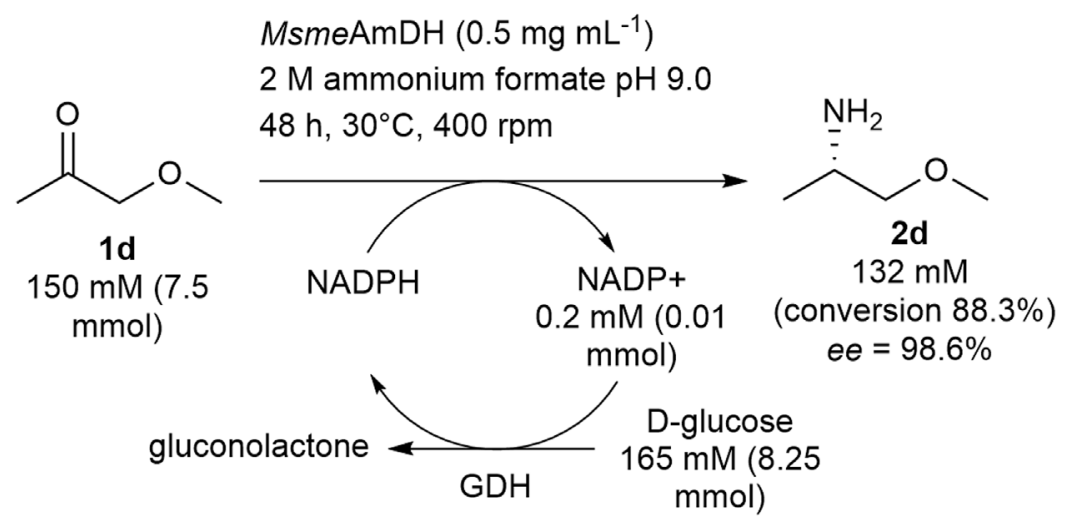

FIGURE 5 | Semi-preparative synthesis of (S)-1-methoxypropan-2-amine (S)-2d

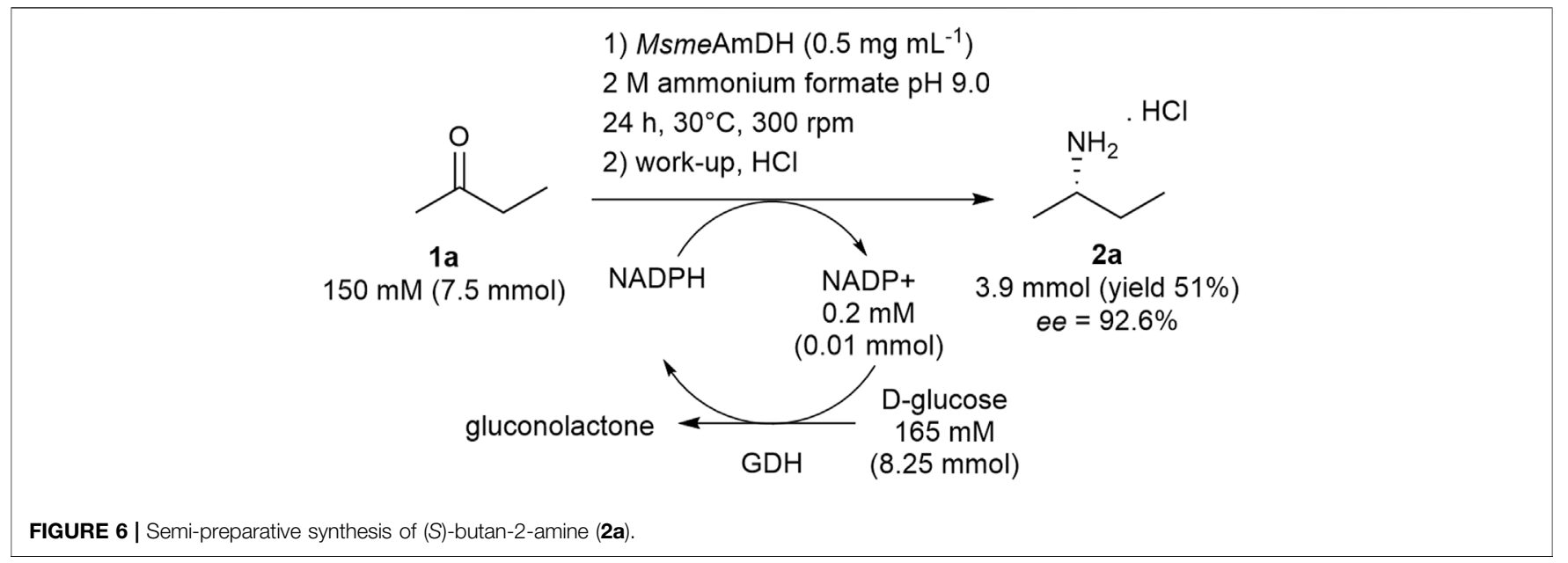

curves, $6.6 \mathrm{mmol}$ of $(S)$-MOIPA was formed $(88.3 \%$ conversion, $e e=98.6 \%)$, superior to the result on the $100-\mu$ l scale, probably due to a better control of the reaction conditions at larger scale (Figure 5). Isolation of the product was not performed due to high water solubility and volatility of the product but the established industrial synthesis of this compound is evidence for the feasibility of this process step.

The synthesis of $2 \mathrm{a}$ was also carried out at the $7.5 \mathrm{mmol}$ scale at $150 \mathrm{mM}$ substrate concentration over $24 \mathrm{~h}$ with $0.5 \mathrm{mg} \mathrm{ml}^{-1}$ of MsmeAmDH. The resulting conversion (>99\%) was again higher than the one obtained at the $100-\mu \mathrm{l}$ scale. Following a similar protocol to the one described by Heckmann et al., the desired (S)butan-2-amine (2a) was isolated thanks to a distillation procedure with $51 \%$ yield and $92.6 \%$ ee after added lyophilization step (Figure 6).

\section{Modeling Studies}

Taking advantage of the crystallographic structures of MsmeAmDH and CfusAmDH with their cofactor $\mathrm{NADP}^{+}$ (PDB ID: 6IAQ and 6IAU, respectively), molecular docking using some tested amines and the closed form of
MsmeAmDH-NADP ${ }^{+}$or CfusAmDH-NADP+ were performed using Autodock software (Morris et al., 2009). In addition, MicroAmDH was modeled by homology using the closed form of MsmeAmDH (PDB ID: 6IAQ) as a template, as already described for MATOUAmDH2 with CfusAmDH as a template (Caparco et al., 2020). Molecular docking was performed on these models following the same procedure as on MsmeAmDH or CfusAmDH. Among the fifty docking conformations obtained from the docking simulations (docking protocol detailed in Materials and Methods), the ratio between correct conformations harboring $(S)$-stereochemistry and those having $(R)$-stereochemistry was analyzed (Figure 7). As the final step of the reductive amination mechanism is the transfer of the hydride from $\mathrm{C} 4$ of the nicotinamide ring of the $\mathrm{NAD}(\mathrm{P}) \mathrm{H}$ cofactor to the $\mathrm{C}$ atom of the iminium intermediate to give respectively the oxidized $\mathrm{NAD}(\mathrm{P})^{+}$and the amine product, only conformations having the correct orientation of the hydrogen toward the cofactor were selected.

As detailed in Figure 7, for the butan-2-amine (2a) ligand, a majority of $(S)$-conformations were generated with the correct orientation in CfusAmDH, MsmeAmDH, and MATOUAmDH2, 


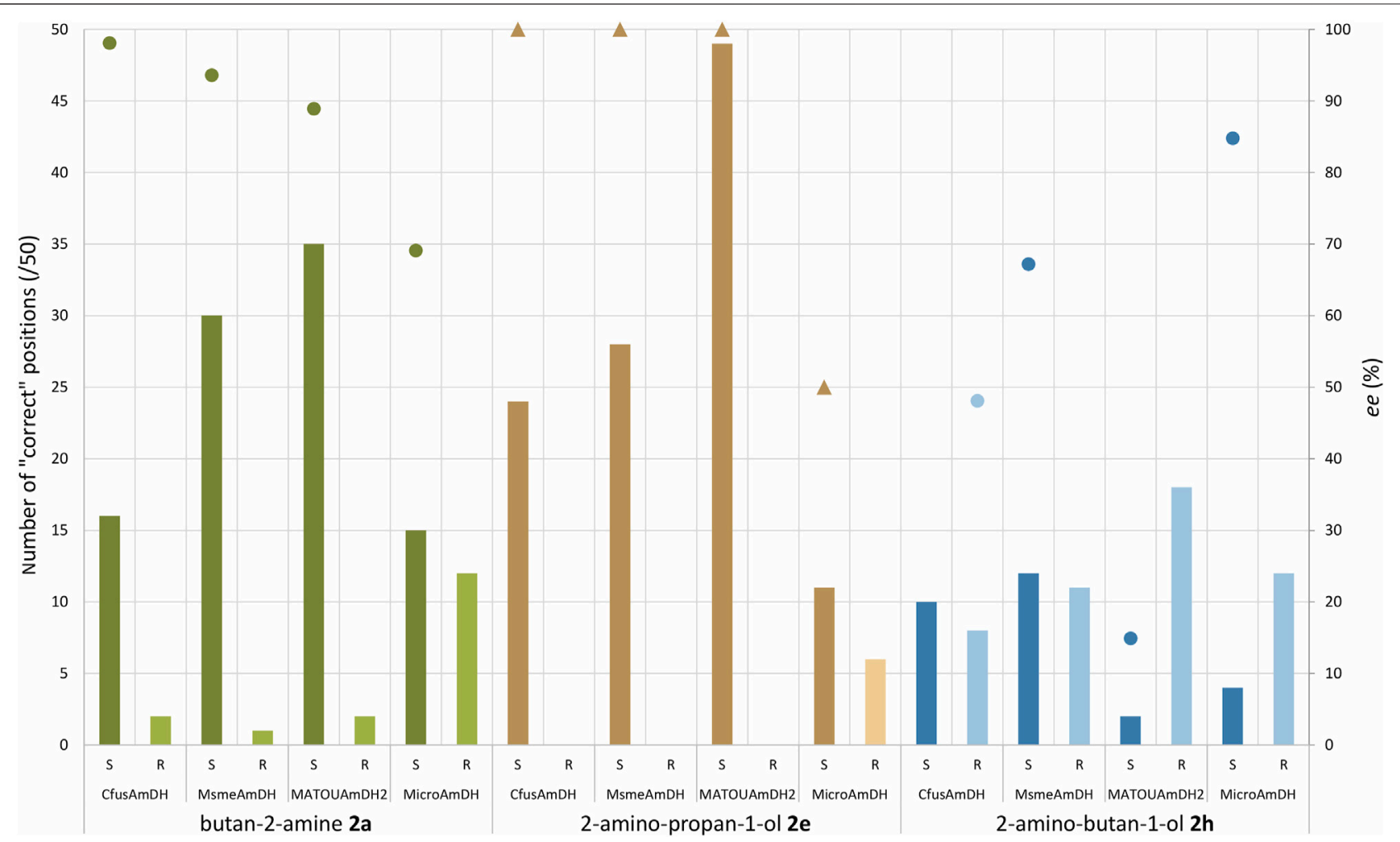

FIGURE 7|Docking simulation of $(S)$ - and (R)-amines 2a, 2e, and 2h. Bars represent the number of "correct" positions obtained out of 50 generated conformations while the scatter plot represents the enantiomeric excess obtained from the corresponding reaction (circles: calculated experimental data, triangles: estimated experimental data). ee values are indicated for (S)-amines except for $\mathbf{2} \mathbf{h}$ with CfusAmDH which is for $(R)$ - $\mathbf{2 h}$. For $\mathbf{2 e}$ ligand, ee values could not be determined but $(R)-\mathbf{2 e}$ was only found in traces with CfusAmDH, MsmeAmDH, and MATOUAmDH2 (ee values arbitrarily indicated at 100\%) but was obtained in larger proportion with MicroAmDH (ee arbitrarily indicated at 50\%).

respectively 16,30 , and 35 out of 50 poses while the $(R)$ conformations gave respectively only 2,1 , and 2 correct positions out of 50 poses. On the other hand, for MicroAmDH, the difference is much lower with 15 out of 50 poses of $(S)$-conformations and 12 out of 50 poses of $(R)$ conformations. These in silico results are in accordance with the experimental data that showed good ee values for the first three enzymes (88.9\%-98.1\%) while MicroAmDH reached only a $69.1 \%$ ee with this substrate.

Based on the docking results, the different $(R) /(S)$ ratios are difficult to explain as the positioning of the docked amines in their $(R)$ and $(S)$ conformations is almost identical, as illustrated in Figure 8 in the case of $M s m e A m D H$. No clear correlation between residues surrounding the substrate, or residues of the second layer, and the docking results with each enzyme could be established. Possibly, the features of the docking algorithm, such as the assumption of rigid protein and ligand, can obscure the reasons for these differences in enantioselectivity.

A good correlation between in silico and in vitro results was observed with the 2-amino-propan-1-ol (2e) ligand, for which only $(S)$-enantiomers were obtained both from these docking studies and from the biocatalytic reactions with CfusAmDH, MsmeAmDH, and MATOUAmDH2. Without being quantified, some $(R)-2 e$ was only experimentally identified with MicroAmDH while also being docked in 35\% correct conformations [11/50 for (S)-conformation against $6 / 50$ for $(R)$-conformation]. This different enantioselectivity and $(R)-/$ (S)-ratios obtained with MicroAmDH with $2 \mathrm{e}$ can be due to a coordination by hydrogen bonding of the hydroxyl group of the ligand with the hydroxyl group of Y169 (P11), which can favor the positioning of the ketone for the formation of the corresponding $(R)$-amine (Figure 9). If we use the nomenclature already published (Mayol et al., 2019), where the residues composing the active site pocket were renamed as their spatial positions $\mathrm{P} 1$ to $\mathrm{P} 20$, this key residue is P11. Both mechanistic and structural roles have been postulated for P3 as the catalytic residue while P11 was hypothesized to be essential for the closing of the active site (Mayol et al., 2019). As a reminder, alignment of these $\mathrm{P} 1-\mathrm{P} 20$ residues in the studied AmDHs is presented in Figure 10.

In CfusAmDH and MATOUAmDH2, P11 is also occupied by $\mathrm{Y}$, respectively $\mathrm{Y} 173$ and Y176, but with a slightly different position that moves the hydroxyl group further away from the ligand $(\Delta=0.4 \AA$ between Y169 of MicroAmDH and Y173 of CfusAmDH, and $\Delta=0.8 \AA$ between Y169 of MicroAmDH and Y176 of MATOUAmDH2). In addition, the more hindered W164 (P9) in MicroAmDH compared to Y168 and Y171 in CfusAmDH and MATOUAmDH2 can also impart less flexibility to the 


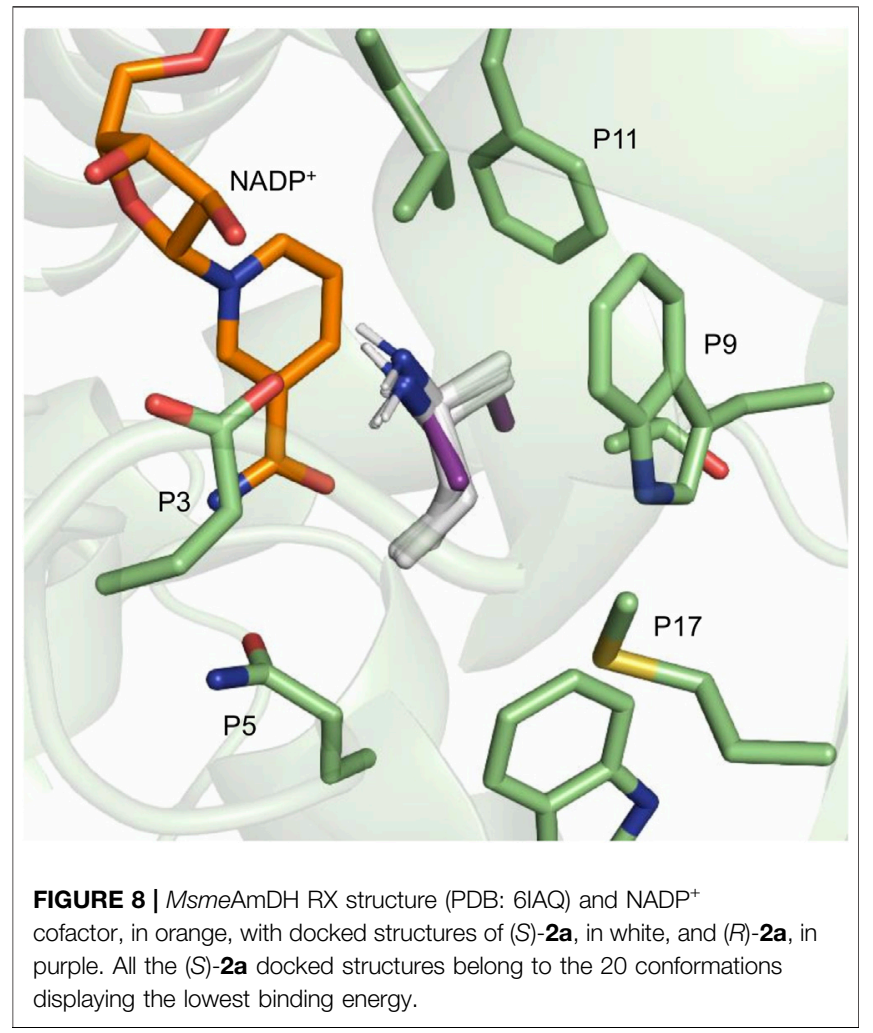

alkylhydroxyl chain. In the docking poses, the latter is oriented more towards Y169 in MicroAmDH and its hydroxyl group, increasing access to $(R)$-configurations. In $M s m e A m D H, P 11$ is occupied by a phenylalanine that cannot provide a hydrogen bond with the substrate to favor the formation of the $(R)$-amine. In that case, only $(S)$-2e can be docked with the hydroxyl group orientated towards the carboxylate function of the glutamate in P3, with which a hydrogen bond can occur (Figure 8).

For 2-aminobutanol (2h) ligand, overall, the in silico analysis revealed much more $(R)$-poses with all the enzymes compared to the other ligands, which is in accordance with the in vitro analysis displaying the lowest $e e$ values for this amine. For example, in $M s m e A m D H$, approximately the same number of $(S)$ - and $(R)$ correct poses were obtained, and the ee value for the $(S)$-2h was experimentally $67 \%$. Nevertheless, the higher ees obtained experimentally for MicroAmDH and $\mathrm{MsmeAmDH}$ compared to MATOUAmDH2 and CfusAmDH are not directly related to the respective ratios of correct $(R)$ - and $(S)$-conformations in this modeling study. For example, in MATOUAmDH2, the ratio of $(R) /(S)$ poses was higher than with CfusAmDH, whereas Cfus AmDH facilitated the formation of $(R)-2 \mathbf{h}$ with an ee value of $48 \%$ and MATOUAmDH2 facilitated the formation of (S)-2h with an ee value of $15 \%$. For CfusAmDH and MsmeAmDH, this ratio was similar (respectively $8 / 10$ and $11 /$ 12), whereas $M s m e A m D H$ displayed a clear preference for the formation of $(S)$-2h $(e e=67 \%)$. For CfusAmDH, many $(R)$-poses seemed stabilized with the hydroxyl group of Y173 (Figure 11A), thus explaining the greatest rate of formation of $(R)$-amines compared to other substrates, even if the ee value remained low $\left(\mathrm{ee}_{(R)}=48.1 \%\right)$. The more hindered ethyl moiety of $(R)$ $\mathbf{2 h}$, compared to $(R)-\mathbf{2 e}$, might "push" the rotation of the substrate, still keeping the chiral center close to the $\mathrm{NADP}^{+}$ hydride carbon, and make the hydroxyl group closer to the tyrosine even in CfusAmDH (2 $\AA)$ and MATOUAmDH2 (2.9 $\AA$ ). It is noticeable that for MATOUAmDH2 and MsmeAmDH, the different conformations displayed much more variability of positions, explained structurally by the presence of other residues ( $\mathrm{P} 5, \mathrm{P} 8, \mathrm{P} 9, \mathrm{P} 16$, and P17) surrounding these key positions, thus enabling other interactions and positioning of the key residues potentially less visible in these models (Figure 11B).

\section{DISCUSSION}

In addition to the protein engineering work that can be performed to access valuable biocatalysts, the deep characterization of wild-type enzymes selected from biodiversity is also a very efficient strategy. This study showed that recently described native AmDHs (CfusAmDH, MsmeAmDH, MicroAmDH, and MATOUAmDH2) appear as suitable biocatalysts for sustainable access to very small chiral amines. This was exemplified by moderate to high conversion rates obtained with 2-amino C3-C5 alkanes at high substrate loadings, and with hydroxylated 2-aminoalkanes such as (3S)-3-aminobutan-2-ol (2g)

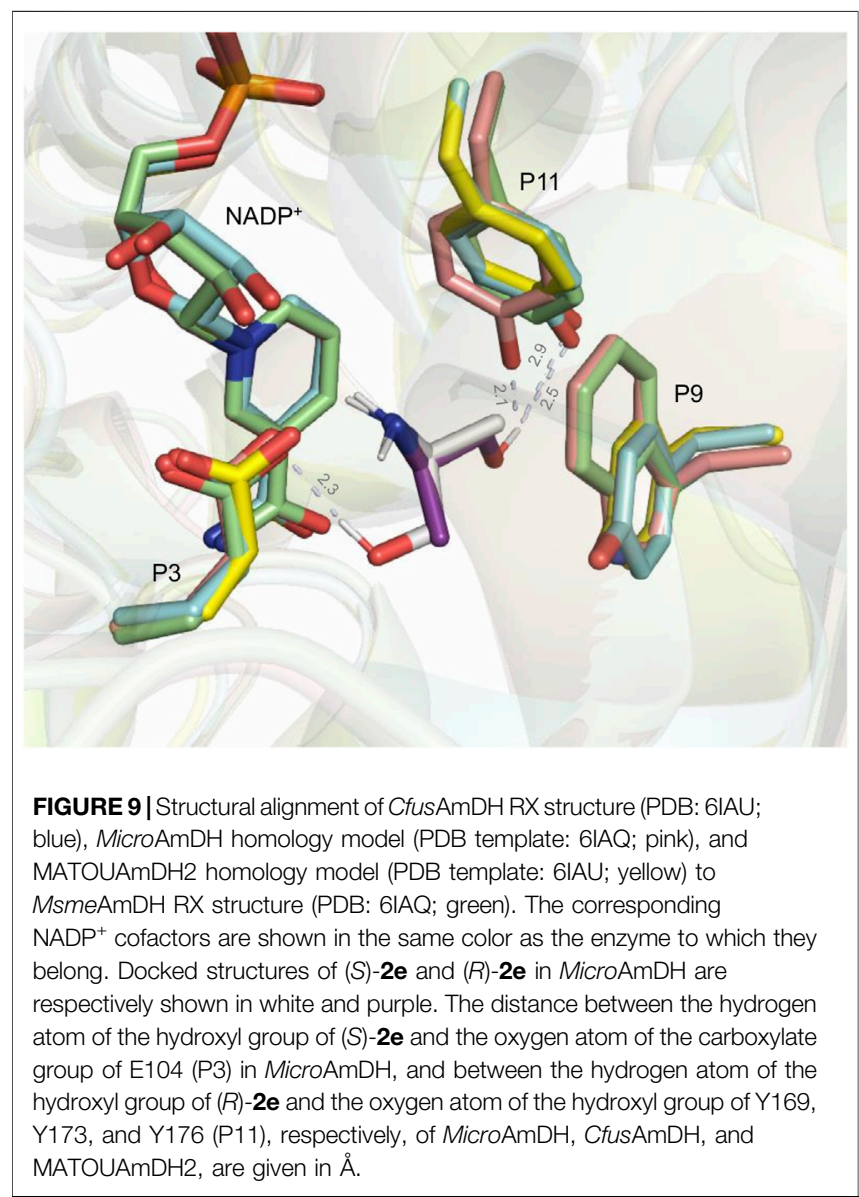




\begin{tabular}{|c|c|c|c|c|c|c|c|c|c|c|c|c|c|c|c|c|c|c|c|c|}
\hline & P1 & P2 & P3 & P4 & P5 & P6 & P7 & P8 & P9 & P10 & P11 & P12 & P13 & P14 & P15 & P16 & P17 & P18 & P19 & P20 \\
\hline CfusAmDH & S84 & G107 & E108 & G139 & Q141 & F144 & W145 & T166 & V168 & N169 & V173 & L177 & H181 & P200 & S201 & V202 & C269 & G271 & T301 & T305 \\
\hline MsmeAmDH & S80 & S103 & E104 & G135 & Q137 & F140 & W141 & A162 & W164 & N165 & F169 & L173 & Q177 & P197 & T198 & F199 & M266 & G268 & T298 & T302 \\
\hline MicroAmDH & S80 & S103 & E104 & G135 & Q137 & F140 & W141 & S162 & W164 & N165 & Y169 & L173 & Q177 & P196 & T197 & F198 & M265 & G267 & T297 & T301 \\
\hline MATOUAmDH2 & S87 & A110 & E111 & G142 & L144 & A147 & C148 & L169 & V171 & N172 & V176 & L180 & H184 & K209 & S210 & V211 & Q278 & G280 & T312 & T316 \\
\hline
\end{tabular}

FIGURE 10 | Comparison of the active site residues P1-P20 of the selected AmDHs. All the P1 to P20 residues listed come from an alignment with CfusAmDH (PDB: 6IAU). The color code used refers to the polarity and charge of the corresponding residue [blue: polar residues, yellow: hydrophobic residues, orange: aromatic residues, red: negatively charged residues, and green: positively charged residues (charges at physiological pH)].

A

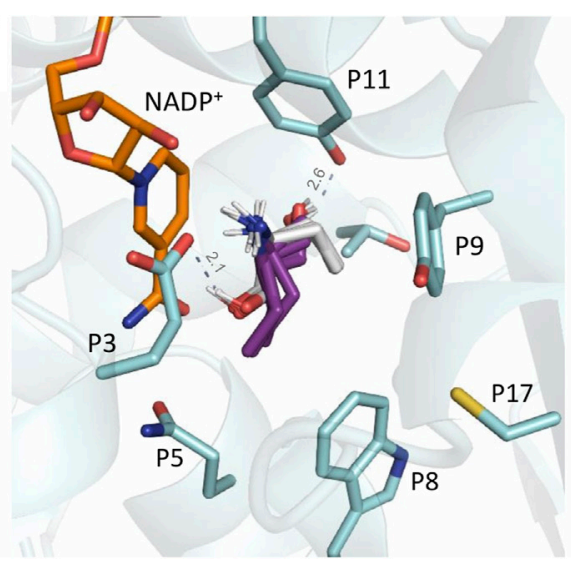

B

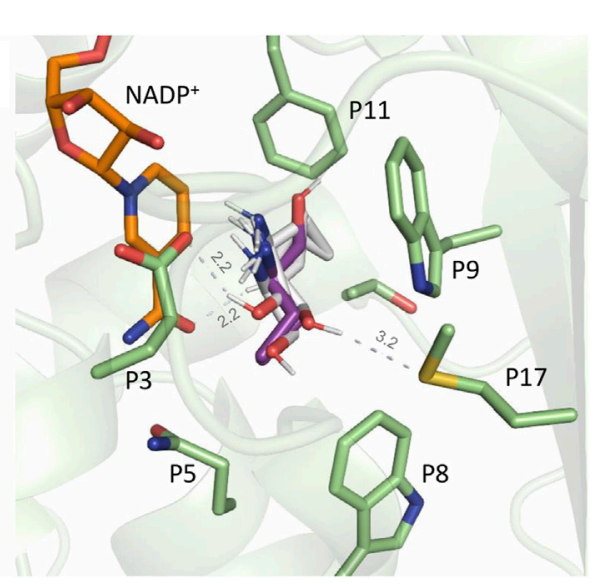

FIGURE 11 | (A) CfusAmDH RX structure (PDB: 6IAU) and NADP ${ }^{+}$cofactor, in orange, with docked structures of (S)-2e, in white, and (R)-2e, in purple; (B) MsmeAmDH RX structure (PDB: 6IAQ) and NADP ${ }^{+}$cofactor, in orange, with docked structures of $(S)$-2e, in white, and (R)-2e, in purple.

and (S)-1-methoxypropan-2-amine (2d), (S)-MOIPA. Despite its modeled larger catalytic pocket, MATOUAmDH2 displayed similar conversion rates and very high ee values, even if it seemed less well adapted for hydroxy ketones. The studied amines, challenging to obtain at high ee values due to inherent similarly sized substituents, are obtained with good to very good ee values with these enzymes. They are therefore positioned perfectly as a complement to the only few enzymes performing chemical reductive amination already described on these small ketones. Particularly, they differ from the imine reductase studied by Johnson-Matthey and Turner's group reported to be active toward 1-methoxypropan-2-one (1d) but with an alkylated amine and not ammonia as amine source, and without further published details (Montgomery et al., 2020). In view of their previously described substrate scope, these native AmDHs clearly displayed preference for small substrates, and particularly these 2aminoketones with C3-C5 carbon chain length, whereas RedAms such as NfRedAm, AtRedAm, or AdRedAm have been shown to be active toward carbon chain of C6 length or above and again mostly with larger amines than ammonia (Sharma et al., 2018; GonzálezMartínez et al., 2020; Mangas-Sanchez et al., 2020). Compared to the engineered enzymes, only the modified AADH L-AmDH-TV was reported to be active toward the short $\mathrm{C} 4$ aliphatic ketones butan-2one (1b). This modified leucine $\mathrm{DH}$ derived from Bacillus stearothermophilus displayed interesting specific activities toward pentan-2-one (1c) $\left(1,303.6 \mathrm{mU} \mathrm{mg}^{-1}\right)$, and, in a lesser extent, toward butan-2-one (1b) (225.5 $\mathrm{mU} \mathrm{mg}^{-1}$ ) (Franklin et al., 2020). The absence of conversion data with these substrates does not allow to compare this enzyme more accurately with our native AmDHs. For the higher homolog 1c, both L-AmDH-TV and the mutant LEAmDH-v1 from the $\varepsilon$-deaminating L-lysine dehydrogenase from Geobacillus stearothermophilus appeared to be more efficient biocatalysts (Tseliou et al., 2019). Nevertheless, their opposite enantioselectivity renders them complementary enzymes to CfusAmDH, MsmeAmDH, and MATOUAmDH2, but not alternative ones. Regarding the hydroxyl-functionalized tested ketones, the studied native AmDHs seemed competitive compared to the mutant $\mathrm{AmDH}-\mathrm{M}_{0}$ displaying very interesting biocatalytic capabilities for the synthesis of different chiral vicinal amino alcohols. Even if no conversion data were reported by Chen et al. for the $\mathrm{C} 3$ amine $\mathbf{2} \mathbf{e}$ and the $\mathrm{C4}$ amine $\mathbf{2 f}$, the commonly studied amine (2S)aminobutan-1-ol (2h) was obtained after a $24 \mathrm{~h}$ reaction with $\mathrm{AmDH}$ $\mathrm{M}_{0}$ with $91 \%$ conversion and $e e>99 \%$ at $30^{\circ} \mathrm{C}$ starting from $50 \mathrm{mM}$ substrate concentration (Chen et al., 2019). Taking into account that the data provided here for hydroxylated ketones may be underestimated due to a study carried out in 96-well plates, and that the work of Chen et al. was performed with a triple amount of purified enzyme, similar conversions (70\%-90\%) may be reached with MicroAmDH for $\mathbf{2 h}$, a precursor of the drug ethambutol. Further improvement should permit higher tolerance to higher substrate concentrations and higher ee values for this substrate. Interestingly, 
the authors suggested a favorable coordination of the hydroxyl group of the ligand with some key residues, as we postulated here with $\mathrm{Y}$ in $\mathrm{P} 11$ in some native AmDHs. In their case, the hydroxyl group of 1-hydroxypentan-2-one may interact with the mutated residue T68, the same as for the carboxylic moiety of the amino acid in the AADH native enzyme. To access amines (S)-2e and (S)-2f via reductive amination, especially with high enantioselectivity, MsmeAmDH and CfusAmDH seemed to be the only described dehydrogenases.

Concerning enzymes not performing reductive amination, many data have been reported with TAs. For example, the $(S)$ 1-methoxypropan-2-one (2d) was synthesized with a $\omega$-TA (Höhne and Bornscheuer, 2009). Despite the completely different mechanism of action between TAs and reductive aminases such as AmDHs, we discussed here some results obtained with TAs to underline the key role of AmDHs in the biocatalytic synthesis of such compounds. Native AmDHs and more particularly MsmeAmDH seemed complementary to HewT or ${ }^{*}$ RTA-X43 used by Heckmann et al. for the continuous-flow synthesis of butan-2-amine (2a). If we refer to the data provided in batch conditions without immobilization for more accurate comparison, MsmeAmDH behaves similarly to HewT or ${ }^{*} \mathrm{RTA}-\mathrm{X} 43$ in terms of conversion increase with higher substrate loadings in the range $10-100 \mathrm{mM}$, but not above. Both TAs displayed similar or higher conversions at $300 \mathrm{mM}$ compared to $100 \mathrm{mM}$, whereas conversions with MsmeAmDH drastically dropped above $150 \mathrm{mM}$. This behavior tends to suggest that these TAs have higher affinity for higher homologs than 1a whereas MsmeAmDH seemed

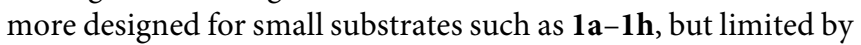
very high substrate loadings. MsmeAmDH favored the formation of the $(S)$-amine like HewT but with higher ee values $(91 \%$ at $150 \mathrm{mM}$ vs. $45 \%$ at $100 \mathrm{mM})$. Further exploration of $\mathrm{AmDH}$ homologs may enable the selection of $(R)$-selective AmDHs for 1a, to provide an alternative to ${ }^{*} \mathrm{RTA}$ $\mathrm{X} 43$, highly stereoselective for the $(R)$-amine formation. Again, protein engineering on $M s m e A m D H$ may also help to improve from the currently good ee value to excellent ee value for this target. As successfully demonstrated by the authors with TAs, scale-up synthesis of $\mathbf{2 a}$ in flow with these AmDHs may provide alternative process systems, also potentially extendable to at least $\mathbf{2 b}-\mathbf{2 d}$, especially as these $\mathrm{AmDH}$ do not require the use of a sacrificial amine donor such as isopropylamine (IPA), which clearly complicates the purification of the target amine. As exemplified in this work, the distillation protocol greatly elaborated by Paradisi et al. for $\mathbf{2 a}$ has been facilitated here by the absence of IPA.

CfusAmDH and MsmeAmDH are also complementary to $R b \mathrm{TA}$, a $(R)$-selective TA applied by $\mathrm{Li}$ et al. for the synthesis of various $(R)$-hydroxyl amines such as $(R)$-ABOL (2f). CfusAmDH and MsmeAmDH harbor a less narrow substrate scope, as $\mathrm{R} b \mathrm{TA}$ can convert $\mathrm{C} 4-\mathrm{C} 7$ ketones, but furnish the opposite $(S)$-enantiomer, thus widening the biocatalytic solutions for accessing such chiral building blocks. Obtained here in non-optimal condition in a 96-well plate with $48 \%-66 \%$ yield with excellent $(S)$-stereoselectivity (ee $>99 \%)$, the opposite enantiomer $(S)-2 f((S)$-ABOL) could be synthesized with MsmeAmDH or CfusAmDH without requiring high loading of IPA as it was done by $\mathrm{Li}$ et al. with $1 \mathrm{M}$ IPA for $100 \mathrm{mM}$ substrate 1f and $30 \mathrm{~g} \mathrm{~L}^{-1}$ of whole cells in $60 \mathrm{~h}$ (Li et al., 2021). Again, Y125 in RbTA was postulated to play a key role in substrate hydroxy ketone recognition by forming a hydrogen bond with the hydroxyl functionality according to docking results and loss of activity with the mutation Y125A, thus supporting our hypothesis of key role of P11 in our case.

The structurally based preliminary explanation of the slight differences in $(S)$-enantioselectivities observed experimentally for $\mathbf{2 a}-\mathbf{2} \mathbf{g}$, together with the important variability for $\mathbf{2 h}$, helps to better understand the enzyme-substrate interactions within the catalytic pockets of these four enzymes. It would be interesting to perform some deeper computational studies, including molecular dynamics simulations, as done by Tseliou et al., to explain the substrate-dependent stereo-switchable selectivity in the case of the mutant LE-AmDH-v1 (Tseliou et al., 2019). In silico studies with the iminium intermediates or carbinolamines, instead of the amine products, may provide additional explanations for the different rates of enantioselectivity observed depending on AmDHs and substrates.

This study highlights the potential of native AmDHs, especially CfusAmDH, MsmeAmDH, MicroAmDH and MATOUAmDH2, for the biocatalytic synthesis of short aliphatic amines and hydroxy amines. For the latter, in one simple step, high conversion rates and ee values can be reached, which is remarkable compared to conventional synthesis. Due to high (S)-enantioselectivity, they are perfectly complementary to the few reductive amination enzymes described for these substrates, which are mostly $(R)$-selective. They are also positioned as very good alternatives to TAs such as ${ }^{*} \mathrm{RTA}-\mathrm{X} 43$. (S)-MOIPA currently produced by the ChiPros ${ }^{\mathrm{TM}}$ process at more than 5,000 tons per year is a nice example of what can be achieved with these native enzymes (non-optimized STY $7.9 \mathrm{~g} \mathrm{~L}^{-1} \mathrm{day}^{-1}$ with $M s m e A m D H)$. Protein engineering work coupled with the structural analysis provided should improve their efficiency and use in chemical synthesis.

\section{DATA AVAILABILITY STATEMENT}

The original contributions presented in the study are included in the article/Supplementary Material. Further inquiries can be directed to the corresponding author.

\section{AUTHOR CONTRIBUTIONS}

$\mathrm{CV}-\mathrm{V}$ conceived the project. LD, CV-V designed and conducted the experiments, with input of $A C$ and $M B . L D$, $\mathrm{GG}$, and $\mathrm{CV}-\mathrm{V}$ analyzed data with input from $\mathrm{AZ}, \mathrm{AB}$, and JC. $\mathrm{LD}$ and $\mathrm{CV}-\mathrm{V}$ wrote the manuscript with input from $\mathrm{GG}, \mathrm{AZ}$, $\mathrm{AC}$, and $\mathrm{AB}$. All authors read and approved the final manuscript. 


\section{FUNDING}

This study was supported by the Commissariat à l'Énergie Atomique et aux Énergies Alternatives (CEA), the CNRS and the University of Evry Val d'Essonne.

\section{ACKNOWLEDGMENTS}

The authors thank P. Wincker and V. de Berardinis for supporting the project, P. Sirvain and A. Perret for large-

\section{REFERENCES}

Ager, D. J., Prakash, I., and Schaad, D. R. (1996). 1,2-Amino Alcohols and Their Heterocyclic Derivatives as Chiral Auxiliaries in Asymmetric Synthesis. Chem. Rev. 96, 835-876. doi:10.1021/cr9500038

Bradford, M. M. (1976). A Rapid and Sensitive Method for the Quantitation of Microgram Quantities of Protein Utilizing the Principle of ProteinDye Binding. Anal. Biochem. 72, 248-254. doi:10.1016/0003-2697(76) 90527-3

Caparco, A. A., Pelletier, E., Petit, J. L., Jouenne, A., Bommarius, B. R., Berardinis, V., et al. (2020). Metagenomic Mining for Amine Dehydrogenase Discovery. Adv. Synth. Catal. 362, 2427-2436. doi:10.1002/adsc.202000094

Chen, F.-F., Cosgrove, S. C., Birmingham, W. R., Mangas-Sanchez, J., Citoler, J., Thompson, M. P., et al. (2019). Enantioselective Synthesis of Chiral Vicinal Amino Alcohols Using Amine Dehydrogenases. ACS Catal. 9, 11813-11818. doi:10.1021/acscatal.9b03889

Cheng, F., Li, Q., Li, H., and Xue, Y. (2020). NAD(P)H-dependent Oxidoreductases for Synthesis of Chiral Amines by Asymmetric Reductive Amination of Ketones. Sheng Wu Gong Cheng Xue Bao 36, 1794-1816. doi:10.13345/ j.cjb.190582

Cosgrove, S. C., Ramsden, J. I., Mangas-Sanchez, J., and Turner, N. J. (2021). "Biocatalytic Synthesis of Chiral Amines Using Oxidoreductases," in Methodologies in Amine Synthesis: Challenges and Applications. Editors A. Ricci and L. Bernardi (Weinheim: Wiley VCH), 243-283. doi:10.1002/ 9783527826186.ch7

Ditrich, K. (2020). "Optically Active Amines on an Industrial Scale," in Amine Biocatalysis (Stuttgart, Germany), 4.

Ducrot, L., Bennett, M., Grogan, G., and Vergne-Vaxelaire, C. (2020). NAD(P)HDependent Enzymes for Reductive Amination: Active Site Description and Carbonyl-Containing Compound Spectrum. Adv. Synth. Catal. 363, 328-351. doi:10.1002/adsc.202000870

Franklin, R. D., Mount, C. J., Bommarius, B. R., and Bommarius, A. S. (2020). Separate Sets of Mutations Enhance Activity and Substrate Scope of Amine Dehydrogenase. ChemCatChem 12, 2436-2439. doi:10.1002/ cctc. 201902364

Gomm, A., and O'Reilly, E. (2018). Transaminases for Chiral Amine Synthesis. Curr. Opin. Chem. Biol. 43, 106-112. doi:10.1016/ j.cbpa.2017.12.007

González-Martínez, D., Cuetos, A., Sharma, M., García-Ramos, M., Lavandera, I., Gotor-Fernández, V., et al. (2020). Asymmetric Synthesis of Primary and Secondary $\beta$-Fluoro-arylamines Using Reductive Aminases from Fungi. ChemCatChem 12, 2421-2425. doi:10.1002/cctc.201901999

Heckmann, C. M., Dominguez, B., and Paradisi, F. (2021). EnantioComplementary Continuous-Flow Synthesis of 2-Aminobutane Using Covalently Immobilized Transaminases. ACS Sustain. Chem. Eng. 9, 4122-4129. doi:10.1021/acssuschemeng.0c09075

Höhne, M., and Bornscheuer, U. T. (2009). Biocatalytic Routes to Optically Active Amines. ChemCatChem 1, 42-51. doi:10.1002/cctc.200900110

Koszelewski, D., Pressnitz, D., Clay, D., and Kroutil, W. (2009). Deracemization of Mexiletine Biocatalyzed by $\omega$-Transaminases. Org. Lett. 11, 4810-4812. doi:10.1021/ol901834x scale purification of the described enzymes, O. Maciejak (University Val d'Essonne) for NMR assistance, and the Region Ile de France for financial support of the $600-\mathrm{MHz}$ spectrometer.

\section{SUPPLEMENTARY MATERIAL}

The Supplementary Material for this article can be found online at: https://www.frontiersin.org/articles/10.3389/fctls.2021.781284/ full\#supplementary-material

Li, F., Liang, Y., Wei, Y., Zheng, Y., Du, Y., and Yu, H. (2021). Biochemical and Structural Characterization of an ( $\mathrm{R}$ )-Selective Transaminase in the Asymmetric Synthesis of Chiral Hydroxy Amines. Adv. Synth. Catal. 363, 4582-4589. doi:10.1002/adsc.202100636

Mangas-Sanchez, J., Sharma, M., Cosgrove, S. C., Ramsden, J. I., Marshall, J. R., Thorpe, T. W., et al. (2020). Asymmetric Synthesis of Primary Amines Catalyzed by Thermotolerant Fungal Reductive Aminases. Chem. Sci. 11, 5052-5057. doi:10.1039/d0sc02253e

Mayol, O., Bastard, K., Beloti, L., Frese, A., Turkenburg, J. P., Petit, J.-L., et al. (2019). A Family of Native Amine Dehydrogenases for the Asymmetric Reductive Amination of Ketones. Nat. Catal. 2, 324-333. doi:10.1038/ s41929-019-0249-z

Montgomery, S. L., Pushpanath, A., Heath, R. S., Marshall, J. R., Klemstein, U., Galman, J. L., et al. (2020). Characterization of Imine Reductases in Reductive Amination for the Exploration of Structure-Activity Relationships. Sci. Adv. 6, eaay9320. doi:10.1126/sciadv.aay9320

Morris, G. M., Huey, R., Lindstrom, W., Sanner, M. F., Belew, R. K., Goodsell, D. S., et al. (2009). AutoDock4 and AutoDockTools4: Automated Docking with Selective Receptor Flexibility. J. Comput. Chem. 30, 2785-2791. doi:10.1002/ jcc. 21256

Mutti, F. G., and Knaus, T. (2021). "Enzymes Applied to the Synthesis of Amines," in Biocatalysis for Practitioners: Techniques, Reactions and Applications. Editors D. G. Gonzalo and I. Lavandera (Weinheim: Wiley VCH), 143-180. doi:10.1002/9783527824465.ch6

Patil, M. D., Grogan, G., Bommarius, A., and Yun, H. (2018a). OxidoreductaseCatalyzed Synthesis of Chiral Amines. ACS Catal. 8, 10985-11015. doi:10.1021/ acscatal.8b02924

Patil, M. D., Grogan, G., Bommarius, A., and Yun, H. (2018b). Recent Advances in $\omega$-Transaminase-Mediated Biocatalysis for the Enantioselective Synthesis of Chiral Amines. Catalysts 8, 254. doi: $10.3390 /$ catal 8070254

Rehn, G., Ayres, B., Adlercreutz, P., and Grey, C. (2016). An Improved Process for Biocatalytic Asymmetric Amine Synthesis by In Situ Product Removal Using a Supported Liquid Membrane. J. Mol. Catal. B: Enzymatic 123, 1-7. doi:10.1016/ j.molcatb.2015.10.010

Sharma, M., Mangas-Sanchez, J., France, S. P., Aleku, G. A., Montgomery, S. L., Ramsden, J. I., et al. (2018). A Mechanism for Reductive Amination Catalyzed by Fungal Reductive Aminases. ACS Catal. 8, 11534-11541. doi:10.1021/ acscatal.8b03491

Slabu, I., Galman, J. L., Lloyd, R. C., and Turner, N. J. (2017). Discovery, Engineering, and Synthetic Application of Transaminase Biocatalysts. ACS Catal. 7, 8263-8284. doi:10.1021/acscatal.7b02686

Tseliou, V., Knaus, T., Masman, M. F., Corrado, M. L., and Mutti, F. G. (2019). Generation of Amine Dehydrogenases with Increased Catalytic Performance and Substrate Scope from $\varepsilon$-deaminating L-Lysine Dehydrogenase. Nat. Commun. 10, 3717. doi:10.1038/s41467-01911509-x

Wu, S., Snajdrova, R., Moore, J. C., Baldenius, K., and Bornscheuer, U. T. (2021). Biocatalysis: Enzymatic Synthesis for Industrial Applications. Angew. Chem. Int. Ed. 60, 88-119. doi:10.1002/anie.202006648

Ye, L. J., Toh, H. H., Yang, Y., Adams, J. P., Snajdrova, R., and Li, Z. (2015). Engineering of Amine Dehydrogenase for Asymmetric Reductive Amination of 
Ketone by Evolving Rhodococcus Phenylalanine Dehydrogenase. ACS Catal. 5, 1119-1122. doi:10.1021/cs501906r

Conflict of Interest: The authors declare that the research was conducted in the absence of any commercial or financial relationships that could be construed as a potential conflict of interest.

Publisher's Note: All claims expressed in this article are solely those of the authors and do not necessarily represent those of their affiliated organizations, or those of the publisher, the editors, and the reviewers. Any product that may be evaluated in this article, or claim that may be made by its manufacturer, is not guaranteed or endorsed by the publisher.

Copyright $\odot 2021$ Ducrot, Bennett, Caparco, Champion, Bommarius, Zaparucha, Grogan and Vergne-Vaxelaire. This is an open-access article distributed under the terms of the Creative Commons Attribution License (CC BY). The use, distribution or reproduction in other forums is permitted, provided the original author(s) and the copyright owner(s) are credited and that the original publication in this journal is cited, in accordance with accepted academic practice. No use, distribution or reproduction is permitted which does not comply with these terms. 